\title{
Low Total Harmonic Distortion and High Power Factor in Parallel Active Power Filter
}

\author{
Yasemin Onal \\ Department of Electrical and Electronics Engineering, \\ Engineering Faculty, Bilecik Seyh Edebali University, Bilecik, Turkey \\ E-mail: yasemin.onal@bilecik.edu.tr \\ Hacer Ucgun \\ Department of Energy Systems Engineering, Institute of Sciences, \\ Bilecik Seyh Edebali University, Bilecik, Turkey \\ E-mail: hacerkozlu223@gmail.com
}

\begin{abstract}
In a modern power system with the increasing use of power electronics components, nonlinear loads connected to the grid cause power quality problems. To overcome the power quality problems, the parallel active power filter PAPF is used in power systems. In this study, the synchronous reference frame based a new control algorithm is proposed for the three-phase PAPF system. In the proposed control algorithm, synchronous reference frame SRF method and moving average filter MAF filter and space vector pulse width modulation SV-PWM technique are used to obtain low total harmonic distortion and high power factor. SRF method and MAF filter are used to calculate the reference current signal. SVPWM technique is used to obtain the switching signals of active switches used in power filters. In the proposed algorithm, the number of measurements is reduced and performance is increased by using source $a b$ currents and ab voltages without filter abc currents and abc voltages and load abc currents. Simulation studies of the proposed control algorithm have been tested using PSIM software. According to the simulation results, it is seen that the proposed control algorithm is more successful in eliminating the harmonics in the source current and compensating the reactive power than the other control method used in the literature.
\end{abstract}

Keywords: Parallel active power filter, Space vector PWM, MAF filter, Power factor, Total harmonic distortion.

DOI: $10.7176 / \mathrm{JSTR} / 5-10-07$

\section{Introduction}

In recent years, due to the rapid growth in industrial technology, electricity consumption is increasing. It is desirable to efficiently and continuously conduct energy without loss [1]. With the increasing use of power electronic components, nonlinear loads connected to the grid cause power quality problems. Power quality problems; voltage fluctuations, voltage unbalance, high harmonic current and voltage, voltage sags, voltage swells and voltage notches [2]. Harmonic current and voltage cause fault of capacitors, noisy operation of electric machines, increased iron and copper losses in used machines and overheating of electronic devices[3].

Passive and active filters are used to elimination power quality problems such as harmonic current and voltage, power factors and reactive power in the literature. The circuit structure of the passive filters is simple, low in cost. But passive filters have some disadvantages such as their large size, the limitations, drawbacks of their usage and constant compensation problem [4]. Due to these disadvantages, parallel active power filter PAPF is used to increase the filter performance[5-7]. The PAPF consist of a threephase voltage source inverter with a DC bus capacitor.

In the literature, there are many control algorithms in the frequency domain [8] and time domain which are applied to PAPF systems successfully. The control algorithms used in the frequency domain are not widely used due to large calculations and time and delay in the calculation of the FFT. In the time domain 
control algorithms used for PAPF, the derivatives of current signal are calculated. Commonly-used time domain control algorithms are the instantaneous active and reactive power based algorithms [9-12], synchronous reference frame SRF based algorithms [3, 13-17]. But, SRF based control algorithms show superior performance compared to PQ based algorithms [18]. In the SRF-based control algorithms, the LPF or HPF is generally used for obtaining the reference current signal and sinusoidal PWM or hysteresis PWM is used for obtaining switching signals [19-21].

In this study, SRF-based a new controller using moving average filter(MAF) and space vector-PWM (SV-PWM) is proposed for three-phase PAPF system. MAF filter and SV-PWM technique are used to obtain the reference current signals used in parallel filter to reduce THD and to increase PF. In the algorithm, the number of measurements is reduced and the performance is improved by using source current and voltage, without load voltage serial and parallel filter current and voltage and load current measurements. Simulation studies of the proposed control algorithm were tested using PSIM software and were compared with other control algorithms used in the literature.

\section{Parallel Active Power Filter}

The P-APF is used to improve power factor, eliminate current harmonics and compensate reactive power [12]. P-APF connects in parallel to the power system as shown in Fig.1. The P-APF contains of a DC capacitor and a voltage source inverter as a voltage source with regulated current controlled.

According to the control algorithm, the compensating currents and the switching signals are obtained by using sinusoidal PWM technique.

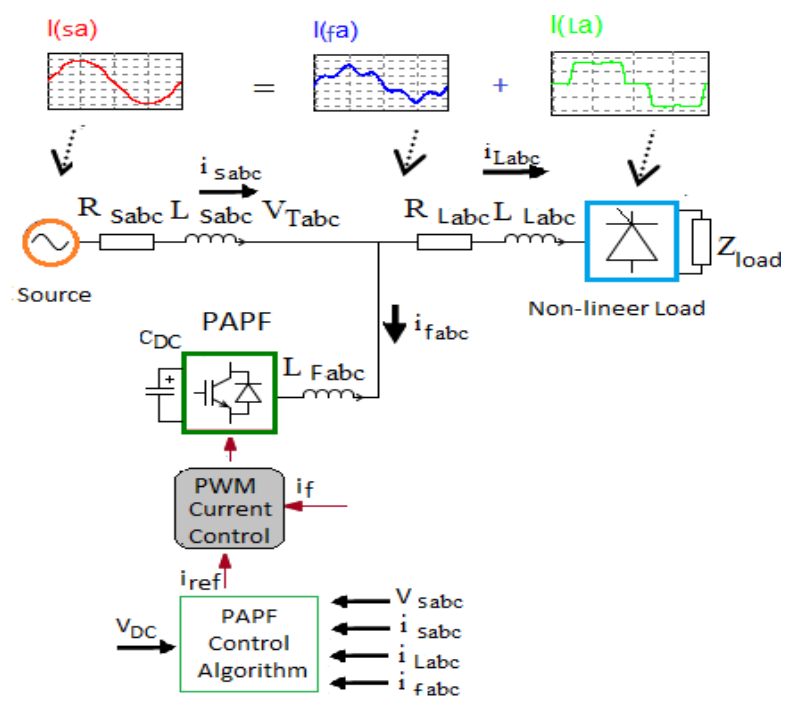

Figure 1. Parallel active power filter.

\subsection{Heading 2}

SRF control algorithm is used in P-APF. The source voltages $\left(\mathrm{V}_{\mathrm{Sabc}}\right)$, DC bus voltage $\left(\mathrm{V}_{\mathrm{dc}}\right)$, source currents $\left(i_{S a b c}\right)$ or load currents $\left(i_{L a b c}\right)$ are realized by taking a total of seven measurement values in the conventional SRF control algorithm [9].

In the conventional SRF algorithm, the $d$ and $q$ values of the source or load currents are obtained by using Eq. (1) with the transformation of dq0 which is known as park transformation (the Park transform). The wt angle is used in the park transformation. The PLL circuit is used to obtain the wt transformation angle.

$$
\begin{aligned}
& \mathrm{i}_{\mathrm{d}}=\frac{2}{3}\left(\cos (w \mathrm{t}) \mathrm{i}_{\mathrm{a}}+\cos \left(w t-\frac{2 \pi}{3}\right) \mathrm{i}_{\mathrm{b}}+\cos \left(w t+\frac{2 \pi}{3}\right) \mathrm{i}_{\mathrm{c}}\right) \\
& \mathrm{i}_{\mathrm{q}}=\frac{2}{3}\left(\sin (w \mathrm{t}) \mathrm{i}_{\mathrm{a}}+\sin \left(w \mathrm{t}-\frac{2 \pi}{3}\right) \mathrm{i}_{\mathrm{b}}+\sin \left(w \mathrm{t}+\frac{2 \pi}{3}\right) \mathrm{i}_{\mathrm{c}}\right) \\
& \mathrm{i}_{0}=\frac{2}{3}\left(\frac{1}{2} \mathrm{i}_{\mathrm{a}}+\frac{1}{2} \mathrm{i}_{\mathrm{b}}+\frac{1}{2} \mathrm{i}_{\mathrm{c}}\right)
\end{aligned}
$$


The obtained $d$ value is passed from LPF. The loss current ( $\left.i_{\text {dloss }}\right)$ is obtained from DC bus voltage with the comparison of the desired voltage value and by passing through a PI controller and LPF filter. The obtained value from LPF output is added to the loss current to decrease DC component voltage fluctuation as shown in Eq. (2).

$$
\mathrm{i}_{\mathrm{d}}^{\prime}=\mathrm{i}_{\text {dloss }}+\mathrm{LPF}\left(\mathrm{i}_{\mathrm{sd}}\right), \mathrm{i}_{\mathrm{q}}^{\prime}=0, \mathrm{i}_{0}^{\prime}=0
$$

The reference source or load currents $i_{a}^{\prime}, i_{b}^{\prime}, i_{c}^{\prime}$ are calculated from the obtained $\mathrm{i}_{\mathrm{d}}^{\prime}, \mathrm{i}_{\mathrm{q}}^{\prime}=0$ and $\mathrm{i}_{0}^{\prime}=$ 0 using the inverse park transformation in Eq. (3).

$$
\begin{aligned}
& i_{a}^{\prime}=\cos (w t) i_{d}+\sin (w t) i_{q}+i_{0} \\
& i_{b}^{\prime}=\cos \left(w t-\frac{2 \pi}{3}\right) i_{d}+\sin \left(w t-\frac{2 \pi}{3}\right) i_{q}+i_{0} \\
& i_{c}^{\prime}=\cos \left(w t+\frac{2 \pi}{3}\right) i_{d}+\sin \left(w t+\frac{2 \pi}{3}\right) i_{q}+i_{0}
\end{aligned}
$$

The obtained $i^{\prime}{ }_{a}, i_{b}^{\prime}, i_{c}^{\prime}$ are compared with the sensed $i_{a}, i_{b}, i_{c}$ and the switching signals for parallel inverter are obtained using sinusoidal-PWM or hysteresis-PWM technique.

\section{Theory and Modeling}

\subsection{Space Vector Pulse Width Modulation (SVPWM)}

In the SVPWM technique, the aim is achieved to reveal the sinusoidal output voltage with the lowest switching loss and the lowest total harmonic distortion. For this, the possible switching states of the IGBT switches in the P_APF are expressed by a switching vector and are used with different combinations of these vectors. The most suitable switching scheme is selected. In this technique, the comparison isn't made in the determination of switching signals. The on-off times of the IGBT's are determined digitally. The basis of the SV-PWM technique is based on the 3 three-phase voltage vectors of the synchronous motor can be converted into a single rotary vector. Three-phase voltages at the desired amplitude and phase are obtained to create a three lag inverter output from a constant DC voltage with SV-PWM. These three-phase voltages are represented by the space vector [22].

SV-PWM is considered to be a preferable technique of PWM applications, as it improves harmonic performance, reduces THD and provides better basic output voltage. Fig.2 shows d-q space vector coordinates of SV-PWM.

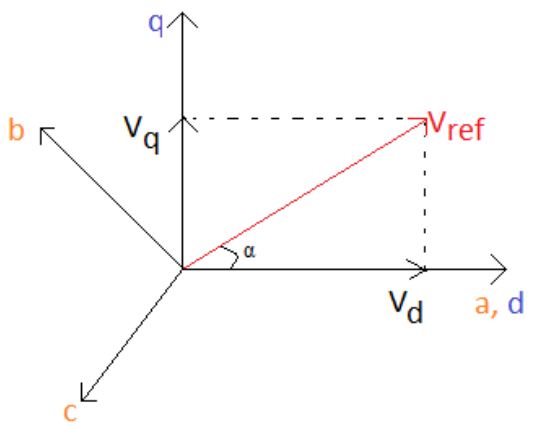

Figure 2. Voltage dq coordinates

The d-q values of the abc voltages are calculated using Eq. (4). 


$$
\begin{aligned}
& V_{d}=V_{s a}-V_{s b} \cos 60-V_{s c} \cos 60 \\
& V_{q}=V_{s b} \cos 30-V_{s c} \cos 30
\end{aligned}
$$

The magnitude $\overline{V_{\text {ref }}}$ and angle $\alpha$ of the rotating vector are calculated using Eq. (5) and Eq. (6).

$$
\begin{aligned}
& \left|\overline{V_{\text {ref }}}\right|=\sqrt{V_{d}^{2}}+\sqrt{V_{q}^{2}} \\
& \alpha=\tan ^{-1}\left(\frac{V_{q}}{V_{d}}\right)=\omega_{s} t=2 \pi f t
\end{aligned}
$$

After this transformation, six active vectors and two zero vectors appear [23]. Using the Eq. (7), the time change between sectors 1 and $6\left(\mathrm{~S}_{1}-\mathrm{S}_{6}\right)$ is determined $\left(\mathrm{n}=1,2, \ldots, 6\right.$ and $\left.0 \leq \alpha \leq 60^{\circ}\right)$. Here $\mathrm{T}_{\mathrm{m}}$ and $\mathrm{T}_{\mathrm{m}+1}$ values are the application time of the voltages. $\mathrm{T}_{0}$ is the application time of the zero voltage vector $\left(\mathrm{V}_{0}\right.$ or $\mathrm{V}_{7}$ ) [24].

$$
\begin{aligned}
& T_{m}=T_{s} m \frac{\sqrt{3}}{2} \sin \left(\frac{n}{3} \pi-\alpha\right) \\
& T_{m+1}=T_{s} m \frac{\sqrt{3}}{2} \sin \left(\alpha-\frac{n-1}{3} \pi\right) \\
& T_{0}=T_{s}-T_{1}-T_{2}
\end{aligned}
$$

The total of 6 space vectors are formed when the output voltages are studied for the period $\mathrm{T}$ and when the $V_{\text {ref }}$ voltage vector is examined in the dq axis. These vectors are placed at $60^{\circ}$ degree intervals in the standing axis tool. The switching states vary in each region. Fig. 3 shows the switching states for sector 1 and sector 4. SV-PWM technique does not require carrier and reference wave forms such as sinusoidalPWM technique.

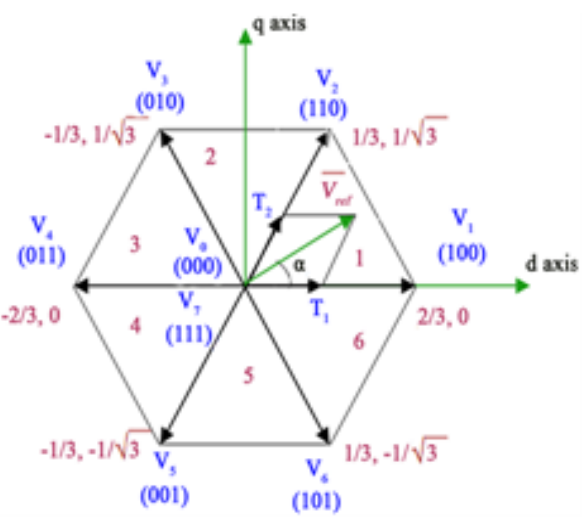

Figure 3. Switching space vector.

\subsection{Moving Average Filter MAF}

Moving average filter is used to improve dynamic filtering response. The discrete transfer function is calculated with Eq. (8) for modelling the MAF. n, denotes the number of sampling data used to derive average amounts.

$$
H(z)=n^{-1}\left(1+\frac{1}{z^{1}}+\frac{1}{z^{2}}+\cdots+\frac{1}{z^{n-1}}\right)=\frac{1}{n} \frac{1-z^{-n}}{1-z^{-1}}
$$

Fig. 4 shows the structure of the MAF consisting of the integration block, the delay block, the subtraction block and the division block [25]. 


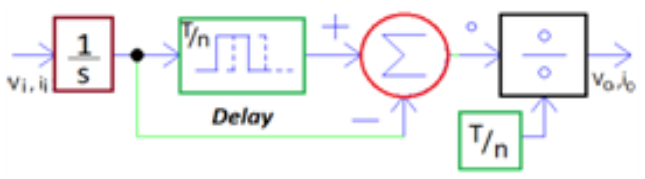

Figure 4. MAF control block

The integration of the voltage signal is obtained by using the integration block. The input voltage signal is delayed by the delay block. Thus, the difference between the output of the delay block and the integration block are obtained to the $\mathrm{t}-\mathrm{T} / \mathrm{n}$ and $\mathrm{t}$ time interval. The output of the subtraction block is sent to the division block. Thereby, the output of the MAF is the moving average of the voltage signal calculated [26] with Eq. (9). Where Vs(t) is the voltage input signal of the MAF.

$$
\text { MAF }_{\text {out }}=\frac{\mathrm{n}}{\mathrm{T}} \int_{\mathrm{t}-\frac{\mathrm{T}}{\mathrm{n}} \mathrm{t}}^{\mathrm{V}} \mathrm{s}(\mathrm{t}) \mathrm{dt}
$$

\subsection{Proposed Control Algorithm}

In the proposed controller, the MAF is used instead of classical LPF to improve the dynamic filtering response and THD and the SV-PWM is used instead of the sinusoidal-PWM to improve the switching performance. Fig. 5 shows the block schema of SRF-based proposed controller.

The ab source voltages $\left(\mathrm{V}_{\mathrm{Sab}}\right)$, ab source currents $\left(\mathrm{i}_{\mathrm{Sab}}\right)$, and DC bus voltage $\left(\mathrm{V}_{\mathrm{dc}}\right)$ are realized by taking five measurement values in the proposed control algorithm.

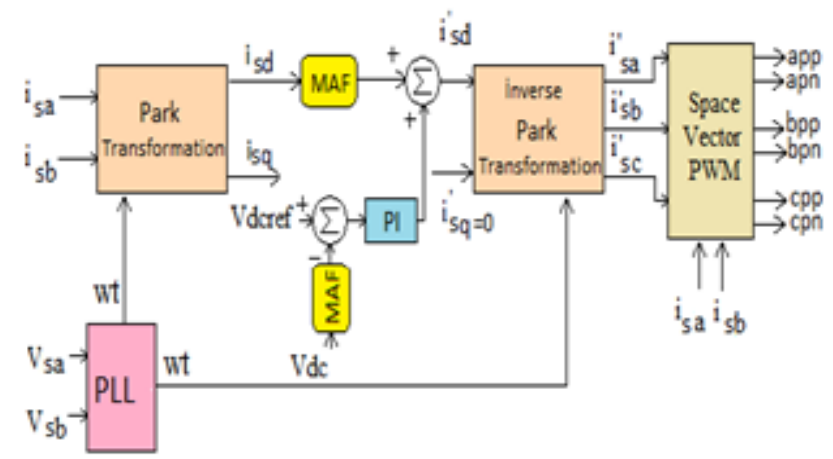

Figure 5. The proposed control schema of the synchronous reference frame algorithm

PLL circuit is used to obtain the wt transformation angleas shown in Fig. 6.

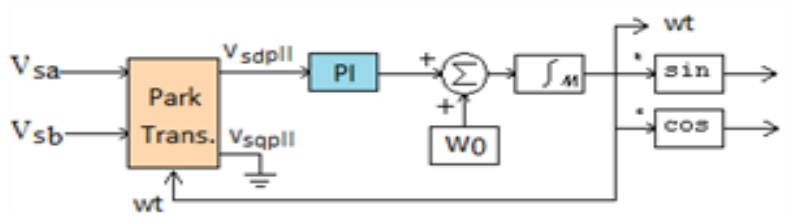

Figure 6. PLL control circuit

The phase $\mathrm{c}$ of the voltage used as the input voltage of the PLL block diagram is calculated by Eq. (10). 
$\mathrm{V}_{\mathrm{c}}=-\mathrm{V}_{\mathrm{sa}}-\mathrm{V}_{\mathrm{sb}}$

The d- $q$ values $V_{\text {dpll }}$ and $V_{q p l l}$ of the source abc voltages are obtained by using Eq. (11).

$$
\begin{aligned}
& v_{d p l l}=\frac{2}{3}\left(\cos (w t) v_{a}+\cos \left(w t-\frac{2 \pi}{3}\right) v_{b}+\cos \left(w t+\frac{2 \pi}{3}\right) v_{c}\right) \\
& v_{q p l l}=\frac{2}{3}\left(-\sin (w t) v_{a}-\sin \left(w t-\frac{2 \pi}{3}\right) v_{b}-\sin \left(w t+\frac{2 \pi}{3}\right) v_{c}\right) \\
& v_{0}=\frac{2}{3}\left(\frac{1}{2} v_{a}+\frac{1}{2} v_{b}+\frac{1}{2} v_{c}\right)
\end{aligned}
$$

The $\mathrm{V}_{\mathrm{dpll}}$ is passed through the PI controller and the references are added to the fundamental angular frequency $(2 \pi \mathrm{f})$. Finally, a wt is obtained by the integration of this calculation [15].

In the proposed control algorithm, only two source currents $\left(i_{\mathrm{sa}}\right.$ and $\mathrm{i}_{\mathrm{sb}}$ ) are enough to measure and the other current $\left(i_{\mathrm{sc}}\right)$ is calculated as given in Eq. (12).

$$
i_{s c}=-i_{s a}-i_{s b}
$$

In the P-APF, the $d-q$ values of the source abc currents $\left(i_{s a}, i_{s b}, i_{s c}\right)$ are obtained by using Eq. (1). The obtained $\mathrm{d}$ value is passed through the MAF filter. The DC voltage is passed the MAF filter and is compared to the reference DC voltage.

The loss current (idloss) is calculated with DC output voltage compared to the desired voltage value and by passing through a PI controller. The obtained current value at the MAF filter output is added to the loss current to decrease DC component voltage fluctuation as shown in Eq. (13).

$$
i_{s d}^{\prime}=i_{\text {dloss }}+\operatorname{MAF}\left(i_{s d}\right), i_{\text {sq }}^{\prime}=0, i_{\mathrm{s} 0}^{\prime}=0
$$

The reference source currents $i_{s a}^{\prime}, i_{s b}^{\prime}, i^{\prime}{ }_{s c}$ are calculated from the obtained $\mathrm{i}_{\mathrm{d}}^{\prime}, \mathrm{i}_{\mathrm{q}}^{\prime}=0$ and $\mathrm{i}_{0}^{\prime}=0$ using the inverse park transformation in Eq. (3). The obtained $i_{s a}^{\prime}, i_{s b}^{\prime}, i_{s c}^{\prime}$ are compared with the sensed $i_{s a}, i_{s b}$ and calculated $i_{s c}$ the switching signals for parallel inverter are obtained using SV-PWM technique.

\section{Results and Discussions}

The steady state and dynamic performances of three phase P-APF system are analyzed by simulating the system in PSIM software. As a load, a nonlinear load with three-phase thyristor is used. The time setting used for the simulation is $0.5 \mathrm{e}-6 \mathrm{~s}$. Fig. 7 shows the PSIM simulation model of the three-phase P-APF. The values using in the simulation model are shown in Table 1.

Table 1. Simulation values

\begin{tabular}{|c|c|c|}
\hline \multirow{4}{*}{ Source } & Voltage $\mathrm{V}_{\text {Sabc }}$ & $190 \mathrm{~V}_{\mathrm{rms}}$ \\
\cline { 2 - 3 } & Frequency f & $50 \mathrm{~Hz}$ \\
\cline { 2 - 3 } & $\mathrm{R}_{\mathrm{sabc}}$ & $10 \mathrm{~m} \Omega$ \\
\cline { 2 - 3 } & $\mathrm{L}_{\mathrm{sabc}}$ & $0.1 \mathrm{mH}$ \\
\hline \multirow{4}{*}{ Load } & 3-phase AC grid resistor $\mathrm{R}_{\mathrm{Labc}}$ & $0.25 \Omega$ \\
\cline { 2 - 3 } & 3-phase AC grid inductance $\mathrm{L}_{\mathrm{Labc}}$ & $1.47 \mathrm{mH}$ \\
\cline { 2 - 3 } & 3-phase DC resistor $\mathrm{R}_{\mathrm{L}}$ & $30 \Omega$ \\
\cline { 2 - 3 } & 3-phase DC inductance $\mathrm{L}_{\mathrm{L}}$ & $11.53 \mathrm{mH}$ \\
\hline \multirow{4}{*}{ P-APF } & AC line inductance $\mathrm{L}_{\mathrm{Fabc}}$ & $3.5 \mathrm{mH}$ \\
\cline { 2 - 3 } & Filter resistor $\mathrm{R}_{\mathrm{F}}$ & $5 \Omega$ \\
\cline { 2 - 3 } & Switching frequency f $\mathrm{f}_{\mathrm{PWM}}$ & $10 \mathrm{kHz}$ \\
\cline { 2 - 3 } & DC Capacitor $\mathrm{C}_{1}$ & $2350 \mu \mathrm{F}$ \\
\cline { 2 - 3 } & DC voltage $\mathrm{V}_{\mathrm{dc}}$ & $400 \mathrm{~V}$ \\
\hline
\end{tabular}




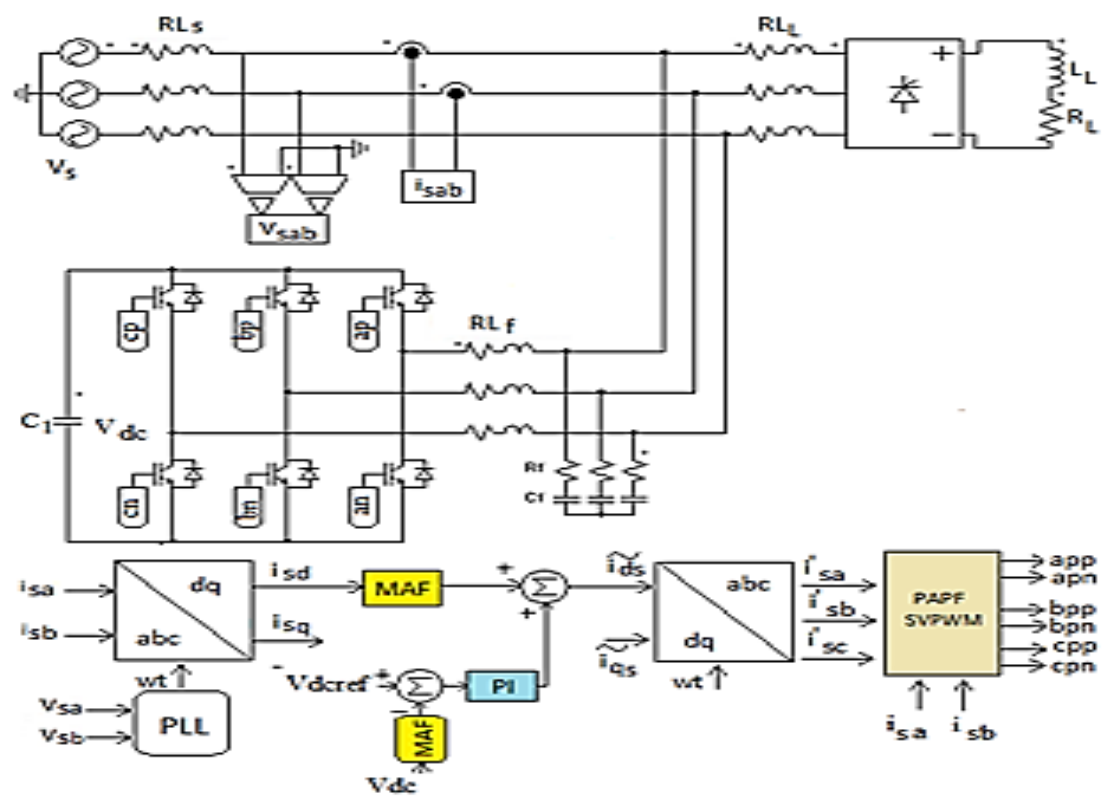

Figure 7. The simulation block P-APF system.

The P-APF is operated as a closed-loop controller by generating the reference filter currents to correct events that cause power quality problems related to nonlinear loads by continuously reading the grid or load currents according to the control algorithm used. The DC voltage must be maintained at a desired value. The reference value must be removed from the measured DC voltage, the fault must be reduced to zero with a transfer function and added to the active current of the control signal.

Fig. 8 shows the effect of P-APF system when the proposed controller is applied. The source current harmonics of $26.31 \%$ is reduced to $0.34 \%$. In the figure, the total harmonic distortion ratio is below the harmonic limit applied in IEEE 519-1992 standards.

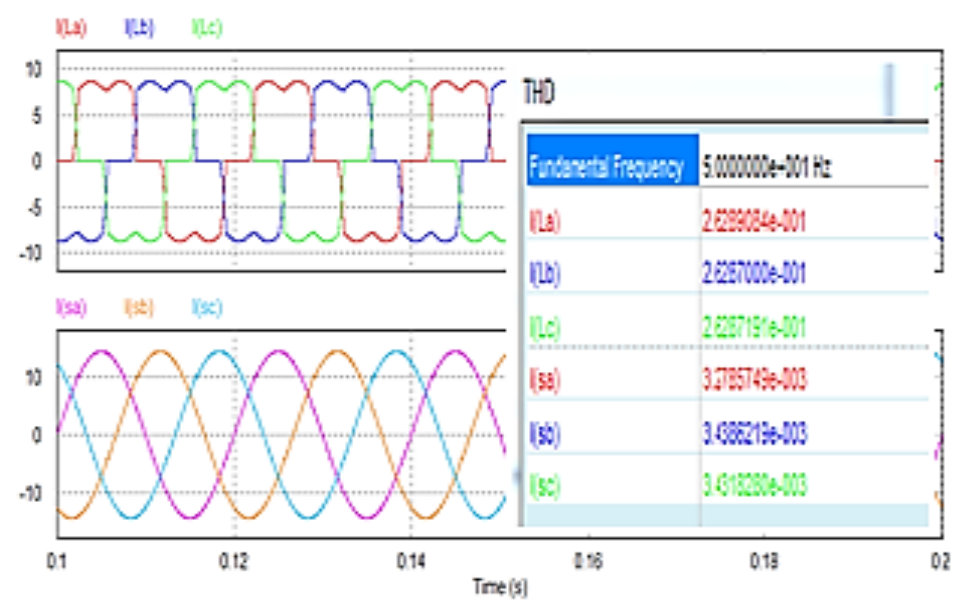

Figure 8. The $\mathrm{i}_{\mathrm{sa}}, \mathrm{i}_{\mathrm{sb}}, \mathrm{i}_{\mathrm{sc}}$ signals and the $\mathrm{i}_{\mathrm{La}}, \mathrm{i}_{\mathrm{Lb}}, \mathrm{i}_{\mathrm{Lc}}$ signals obtained with the proposed control algorithm

The current harmonic compensation capability of the proposed SRF based control algorithm is shown in Fig. 9 as the total harmonic distortion (THD) levels given before and after the filter operation. In the obtained results, the source current harmonic with a ratio of $26.28 \%$ is reduced to $0.34 \%$ with the proposed control algorithm. In addition, the proposed control algorithm is capable of compensating the harmonics and reactive power of the source currents. The simulation results for reactive power compensation are shown in Fig. 10. 

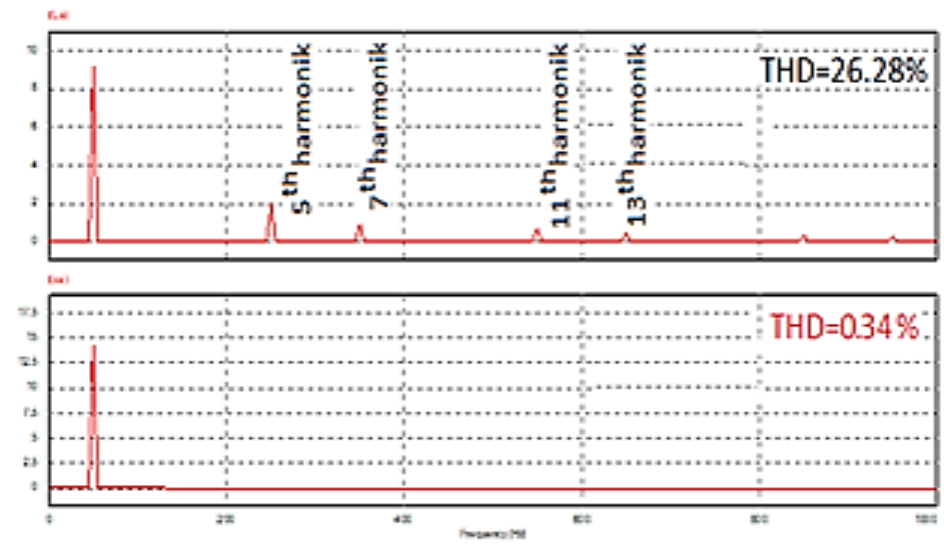

Figure 9. The FFT values of load and source current THD measurement levels before and after proposed control algorithm

The power factor values before and after applying the proposed controller are shown in Fig. 10a and Fig. 10b. The power factor between the load voltage and the source current is measured as 0.9999 after the proposed controller is applied to the P-APF system. The proposed control algorithm has the ability to improve the power factor.

The study of the proposed control algorithm is tested under steady state and transient response. The steady state response of the proposed control algorithm is shown in Fig. 11. Fig. 12 shows the transient response of the proposed controller in case of an P-APF system is applied at $\mathrm{t}=0.15 \mathrm{~ms}$.

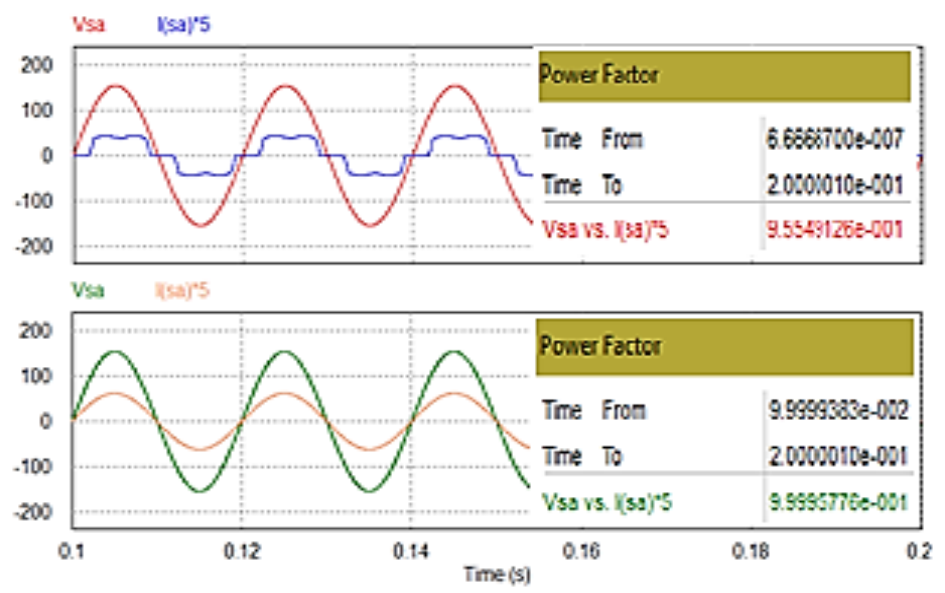

Figure 10. The load voltage and the source current signals for reactive power compensation 


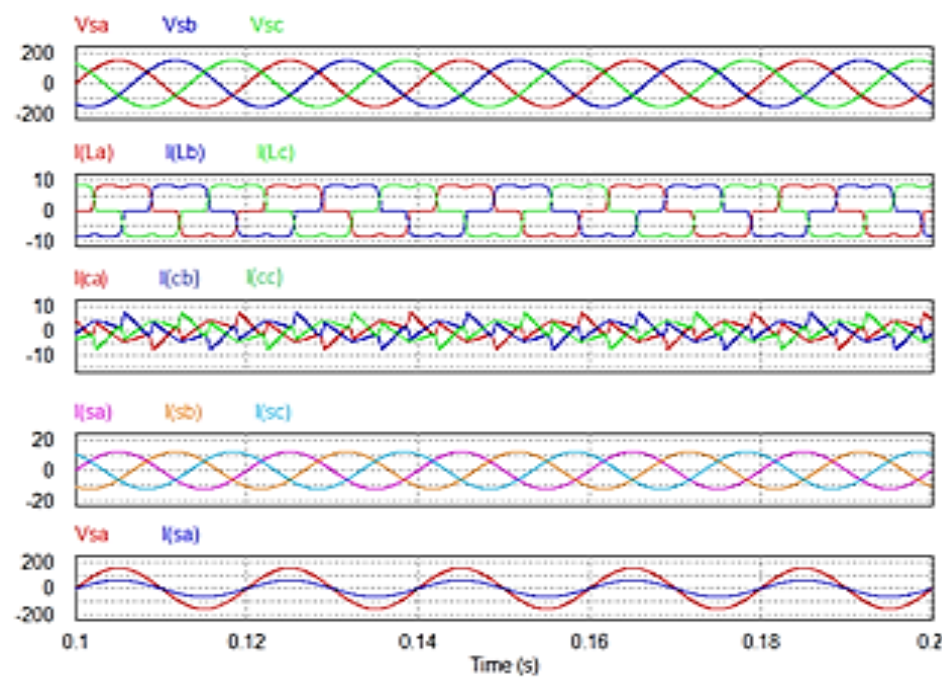

Figure 11. The steady state response of operation of P-APF system for proposed controller a) $\mathrm{V}_{\mathrm{sa}}, \mathrm{V}_{\mathrm{sb}}$ and $\mathrm{V}_{\mathrm{sc}}$ signals, b) $\mathrm{i}_{\mathrm{La}}, \mathrm{i}_{\mathrm{Lb}}, \mathrm{i}_{\mathrm{Lc}}$ signals, c)compensator $\mathrm{i}_{\mathrm{ca}}, \mathrm{i}_{\mathrm{cb}}, \mathrm{i}_{\mathrm{cc}}$ signals, d) $\mathrm{i}_{\mathrm{sa}}, \mathrm{i}_{\mathrm{sb}}, \mathrm{i}_{\mathrm{sc}}$ signals, e) a phase $v_{\mathrm{La}}$ and $i_{\mathrm{sa}}$ signals for power factor value

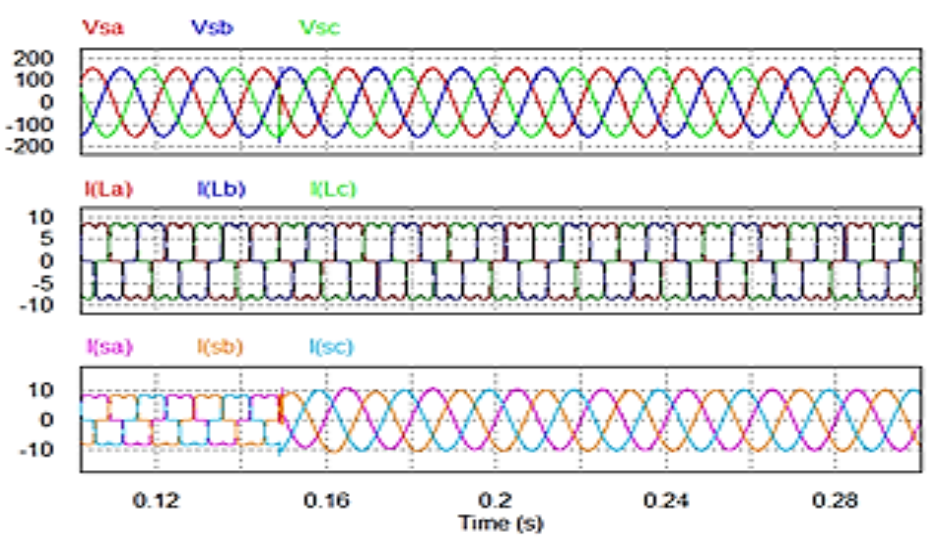

Figure 12. The transient response of operation of P-APF system for proposed controller a) $V_{\mathrm{sa}}, \mathrm{V}_{\mathrm{sb}}$ and $\mathrm{V}_{\mathrm{sc}}$ signals, b) $\mathrm{i}_{\mathrm{La}}, \mathrm{i}_{\mathrm{Lb}}, \mathrm{i}_{\mathrm{Lc}}$ signals, c) $\mathrm{i}_{\mathrm{sa}}, \mathrm{i}_{\mathrm{sb}}, \mathrm{i}_{\mathrm{sc}}$ signals

In Table II, the proposed control algorithm and the other control algorithms used in literature for P-APF are compared. In the simulation studies, when the conventional SRF control algorithm is applied to the P-APF, the THD value of the source current is decreased from $15.81 \%$ to $2.38 \%$. When the SRF-based proposed controller is applied to the P-APF, the THD value of the sources current is decreased to $0.34 \%$.

\section{Conclusions}

A new SRF-based control algorithm which applies a moving average filter and SV-PWM to obtain the reference abc current signals for active power filter is presented and tested in PSIM. In the proposed control algorithm, MAF filter and space vector pulse width the modulation technique are used to produce the switching signals of the active switches used in parallel filters to the reduced THD and improved PF. In the proposed control algorithm, five measurement values are taken from the power system by using ab source voltage, ab source current and DC bus voltage measurements in P-APF. The number of measurements is reduced according to the conventional SRF method. It can be observed that the proposed controller gives the lowest THD value and the highest pf value according to other algorithms used in literature as shown in Table II. According to Table II, it is seen that the proposed control algorithm is more successful in eliminating the harmonic of the source current by improving power factor and compensating the reactive power. 
Table 2. Comparison of the proposed controller and the other controller using for the three-phase UPQC

\begin{tabular}{|c|c|c|}
\hline PAPF algorithm & Before P-APF THD $(\%)$ & After P-APF THD $(\%)$ \\
\hline Self Tuning Filter[16] & $13.92 \%$ & $2.69 \%$ \\
\hline Fuzzy Logic Controller [21] & $25 \%$ & $2.57 \%$ \\
\hline Modified SRF[3] & $29 \%$ & $1.78 \%$ \\
\hline Direct Power Control [12] & 25.95 & $1.54 \%$ \\
\hline Power Balance Theory & & $1.18 \%$ \\
\hline Conventional SRF & \multirow{2}{*}{$26.28 \%$} & $2.38 \%$ \\
\hline Proposed SRF & & $\mathbf{0 . 5 7 \%}$ \\
\cline { 1 - 1 } & & \\
\cline { 1 - 1 } & & \\
\cline { 1 - 1 } & & \\
\hline
\end{tabular}

\section{References}

[1] Ye, J., Gooi, H. B., \& Wu, F. (2016). Optimization of the size of UPQC system based on datadriven control design. IEEE Transactions on Smart Grid, 9(4), 2999-3008.

[2] Graovac, D., Katic, V., \& Rufer, A. (2007). Power quality problems compensation with universal power quality conditioning system. IEEE Transactions on Power Delivery, 22(2), 968-976.

[3] Silva C.H., Pereira R.R., Silva B.E.L., Lambert T.G., \& Bose B.K. (2008). Improving the Dynamic Response of Shunt Active Power Filter using Modified Synchronous Reference Frame PLL. 34th Annual Conference of IEEE Industrial Electronics, pp. 790-795.

[4] Xiu C., \& Liu Y. (2009). Hysteresis Response Neural Network and Its Applications. ISECS International Colloquium on Computing, Communication, Control, and Management, pp. 361364.

[5] Feng, L., \& Wang, Y. (2017). Modeling and resonance control of modular three-level shunt active power filter. IEEE Transactions on Industrial Electronics, 64(9), 7478-7486.

[6] Zaveri, N., \& Chudasama, A. (2012). Control strategies for harmonic mitigation and power factor correction using shunt active filter under various source voltage conditions. International Journal of Electrical Power \& Energy Systems, 42(1), 661-671.

[7] Soomro D.M., Omran M.A., \& Alswed S.K. (2015). Design of A Shunt Active Power Filter to Mitigate the Harmonics Caused by Nonlinear Loads. ARPN Journal of Engineering and Applied Sciences, 10(19), 8774-8782.

[8] Elmitwally, A., Abdelkader, S., \& El-Kateb, M. (2000). Neural network controlled three-phase four-wire shunt active power filter. IEE Proceedings-Generation, Transmission and Distribution, 147(2), 87-92.

[9] Harirchi, F., \& Simoes, M. G. (2018). Enhanced instantaneous power theory decomposition for power quality smart converter applications. IEEE Transactions on Power Electronics, 33(11), 9344-9359.

[10] Priya M.S., \&BaluU.S. (2014). Simulation Results of A Shunt Active Power Filter using P-Q Theory Power Components Calculations, International Journal of Advance Research In Computer Science and Management Studies, 2(2), 247-254.

[11] AkagiH., Kanazawa Y., \& NabaeA. (1994). Instantaneous Reactive Power Compensators Comprising Switching Devices without Energy Storage Components. IEEE Transactions on Industry Applications, 20( 3), 625-630

[12] Mesbahi N., OuariA., OuldAbdeslam D., Djamah T., \& Omeiri A., (2014). Direct Power Control of Shunt Active Filter using High Selectivity Filter (HSF) Under Distorted or Unbalanced Conditions. Electr. Power Syst. Res. 108, 113-123. 
[13] Kesler M., \& Ozdemir E., (2011). Synchronous Reference Frame-Based Control Method for UPQC Under Unbalanced and Distorted Load Conditions. IEEE Transactions on Industrial Electronics, 58(9), 3967-3975.

[14] Mendalek, N., \& Al-Haddad, K. (2000). Modeling and nonlinear control of shunt active power filter in the synchronous reference frame. InNinth International Conference on Harmonics and Quality of Power. Proceedings, 1, 30-35.

[15] Rahmani, S., Mendalek, N., \& Al-Haddad, K. (2010). Experimental design of a nonlinear control technique for three-phase shunt active power filter. IEEE Transactions on Industrial Electronics, 57(10), 3364-3375.

[16] Chebabhi A., Abdelhalim K., \& Fellah F.M.K., (2018). Self Tuning Filter and Fuzzy logic Control of Shunt Active Power Filter for Eliminates the Current Harmonics Constraints under Unbalanced Source Voltages and Loads Conditions. Journal of Power Technologies, 98(1 ), 119.

[17] Patjoshi R.K., \& Mahapatra K., (2017). High-Performance Unified Power Quality Conditioner using Non Linear Sliding Mode and New Switching Dynamics Control Strategy. IET Power Electronics, 10 ( 8), 863-874.

[18] Jeraldine Viji A., Aruldoss T., \& Victoire A.,(2014). Enhanced PLL based SRF control method for UPQC with fault protection under unbalanced load conditions. International Journal of Electrical Power and Energy Systems, 58, 319-328.

[19] Raju N.I., Islam M.S., \& Uddin A.A., (2013). Sinusoidal PWM Signal Generation Technique for Three Phase Voltage Source Inverter with Analog Circuit \& Simulation of PWM Inverter for Standalone Load Micro System. Internatıonal Journal of Renewable Energy Research, 3( 3), 647658.

[20] Sahoo K.S., \& Bhattacharya T., (2018). Phase Shifted Carrier-Based Synchronized Sinusoidal PWM Techniques for a Cascaded H-Bridge Multilevel Inverter. IEEE Transactions on Power Electronics, 33( 1), 513-524.

[21] Patel R. \& Panda A. K., (2014). Real time implementation of PI and fuzzy logic controller based 3 -phase 4-wire interleaved buck active power filter for mitigation of harmonics with id-iq control strategy. International Journal of Electrical Power and Energy Systems, 59, 66-78.

[22] Badran M.A.A., Tahir A.M., \& Faris W.F., (2013). Digital Implementation of Space Vector Pulse Width Modulation Technique Using 8-Bit Microcontroller. World Appl. Sci. J., 21, 21-28.

[23] Lu Y., Xiao G., Wang X., Blaabjerg F., \& Lu D., (20169. Control Strategy for Single-Phase Transformerless Three-Leg Unified Power Quality Conditioner Based On Space Vector Modulation IEEE Trans. Power Electron, 31, 2840-2849.

[24] Shankar M., Monisha S., Shesna H., Vignesh T., Sikkandar N., Sundaramoorthi S., \& Venkatesh S., (2014). Implementation of Space Vector Pulse Width Modulation Technique With Genetic Algorithm to Optimize Unified Power Quality Conditioner. Am. J. Appl. Sci. , 11, 152-159.

[25] Silva S.A.O., \& Negrao F.A., (2018). Single Phase to Three Phase Unified Power Quality Conditioner Applied in Single Wire Earth Return Electric Power Distribution Grids. IEEE Transactions on Power Electronics, 33(5), 3950-3960.

[26] Sriranjani R., \& Jayalalitha S. (2017). Design of Shunt Active Filter using Iterative Method to Mitigate the Harmonics and Reactive Power. Journal of Engineering and Applied Sciences, 12(24), 7239-7249. 